- $\quad$ Alfredo Gastal, PhD em arquitetura (Universidade da Pensilvânia), professor visitante do programa de pós-graduaç̃o em arquitetura da Universidade Federal do Rio Grande do Sul

- UFRGS -, trabalha no Conselho Nacional de Desenvolvimento Científico e Tecnológico -

CNPq.

Geraldo Sá Nogueira Batista, mestre em arquitetura (UnB), M.Phil. (Universidade de Edimburgol. Professor colaborador do programa de pós-graduação em planejamento urbano da Universidade de Brasilia, trabalha no Conselho Nacional de Desenvolvimento Científico e Tecnológico - CNPq.

\title{
O habitat urbano brasileiro: paradigma e perspectivas
}

\section{Os fatos}

A história do desenvolvimento urbano brasileiro como preocupação governamental está, de certa forma, ligada ao problema do desenvolvimento municipal, que se tornou mais intenso a partir da Revolução de 1930. Desde esse momento, nota-se que o conceito de desenvolvimento adotado é associado diretamente aos conceitos de crescimento econômico e eficiência administrativa. 1 Tal postura consolida-se através dos tempos e torna-se uma constante dos discursos tanto dos municipalistas como dos planejadores urbanos.

Esse discuro não se limitou ao plano meramente verbal ou teórico, na medida em que encontrou seu rebatimento num grande número de experiências concretas e se inseriu num processo histórico pontilhado tanto pela fundação de novas capitais (Belo Horizonte, Goiânia e Brasília) como pela criação e desativação freqüente de instituições promotoras de programas habitacionais ou urbanos.

Na promoção das idéias do planejamento podem ser identificadas várias vertentes que, até o fim da década 1960, evoluem distintamente, embora com algumas confluências e superposições. Uma dessas é representada por arquitetos que se inspiravam em doutrinas como a da Cidade Jardim e a do urbanismo do movimento da arquitetura moderna internacional, paradigmatizado na Carta de Atenas. Nessa vertente, localizam-se os planos diretores realizados na Diretoria de Saneamento e na Secretaria de Viação e Obras do Estado do Rio Grande do Sul, a elaboração do Plano Piloto de Brasília, os planos de Goiânia e de Belo Horizonte, da Cidade dos Motores etc. É a vertente do que poderíamos, com certa liberdade, chamar de urbanismo stricto sensu. Uma segunda e importante vertente é constituída pelos profissionais ligados a SAGMACS 2 , ou que gravitavam em torno do Movimento de Economia e Humanismo do padre dominicano francês J. Lebret, que defendiam idéias de planejamento e intervenções fisicas baseadas em pesquisas com conteúdo econômico e social. ${ }^{3}$ Um desdobramento importante desse grupo foi constituído pelos chamados CEMUAMs! ${ }^{4}$

A terceira vertente, de cunho político-administrativo, representada pelos defensores de idéias de modernização administrativa, buscava obter maior peso, autonomia e participação dos municipios na estrutura político-administrativa brasileira. Seus componentes gravitavam em torno da Fundação Getulio Vargas e do Instituto Brasileiro de Administração Municipal e, de um modo ou outro, assumiram posições cujas origens podem ser associadas às da criação do DASP e à introdução das técnicas de planejamento na administração pública nacional.

O momento de maior síntese entre essas três vertentes se dá no período em que se desenvolveram as atividades do Serviço Federal de Habitação e Urbanismo - SERFHAU - , instituição criada juntamente com o BNH após o movimento político-militar de 1964.5 O período $1969-1974$ corresponde ao ápice do prestígio e importância relativa das atividades de planejamento urbano no contexto da estrutura político-administrativa do país. 
Nesse tempo produziram-se inúmeros documentos técnico-normativos - os instrumentos de planejamento - que eram organizados em função do porte da cidade a que se destinavam e que se enquadravam no espírito do PAC - Programa de Ação Concentrada - , lançado em 1969 pelo Ministério do Interior. É também a partir do período de ativação do SERFHAU que se lançaram as bases para um programa sistemático de formação de recursos humanos para o desenvolvimento urbano. Iniciado na COPPE/UFRJ, esse programa hoje se estende para quatro outras universidades (UnB, UFRGS, UF$\mathrm{Pe}, \mathrm{FAU} / \mathrm{USP}$ ).

A produção intelectual heterogênea desse período (1969-1974), porém, acabou por gerar uma série de choques internos no próprio governo, uma vez que a política de desenvolvimento urbano implícita nos planos do SERFHAU era incompatível com a política geral de governo adotada pelo país. Oliveira (1979:111) aponta: "A doutrina do PDLI, por ser diferente da orientação geral do governo central, tornava o planejamento local incompativel e inintegrável; estava configurado o choque entre centralização versus descentralização e planejamento espacial ou regionalista versus planejamento-setorial"

Como resultado, em 1974, o SERFHAU era desativado e, em seu lugar, surgiria na Secretaria de Planejamento da Presidência da República - SEPLAN - a Comissão Nacional de Regiões Metropolitanas e Política Urbana - CPNU. Tal comissão, inicialmente idealizada como um fórum de debates interministerial que visaria à integração das ações e políticas dos diversos setores do governo, em breve tornou-se um Ersatz do SERFHAU, agora porém perfeitamente adequado à orientação centralizadora governamental. Por outro lado, na mesma época, o Ministério do Interior entrou em um processo de esvaziamento de sua liderança multissetorial e, em pouco tempo, sua participação na CNPU restingir-se-ia às acões setoriais do Banco Nacional da Habitação (BNH) nos campos da habitação e saneamento. Paralelamente, surge mais uma grande empresa pública, a Empresa Brasileira de Transportes Urbanos - EBTU - que caracterizaria, junto com a ação do BNH, a orientação setorialista que subsistiria pelos próximos anos.

Esse período, que marca também o desaparecimento quase que completo da ação municipalista do governo federal 6 , é reflexo da crise de identidade enfrentada pela área que, se por um lado propugnava por uma ação econômica e social mais efetiva, por outro não encontrava eco para suas instâncias em estrato algum da sociedade. Refletindo essa crise, até mesmo os cursos de pós-graduação em planejamento urbano foram, paulatinamente, se transformando em centros de estudos urbanos me- ramente acadêmicos, onde a realidade urbana brasileira passaria a ser freqüentemente analisada de acordo com modismos internacionais sociológicos ou econométricos.

Quem quer que faça um balanço desse período, é tentado a considerar o planejamento urbano no país como algo próximo à ficção. Apesar do sucesso relativo de algumas experiências isoladas, $\mathrm{CO}^{-}$ mo a de Curitiba, há hoje um sentimento generalizado de impotência por parte dos planejadores, em face dos problemas urbanos que se agravam em ritmo crescente e constante, assumindo um caráter de quase-insolvência diante da conjuntura econômica atual. Aceitar esse fato não significa, todavia, que estejamos adotando uma posição de descrença em soluções 'viáveis' para o encaminhamento da 'crise' urbana brasileira. Acreditamos que alternativas podem ser realisticamente formuladas, baseadas na superação das tendências ao mimetismo cultural dos planejadores e da visão setorialista do problema urbano. E, sob essa mesma ótica, o reconhecimento do impasse e posicionamento crítico diante do seu próprio processo de formação.

Partindo-se dessa definição de Reina, é possivel admitir-se que cada grupo social urbano tende a possuir características culturais próprias que o diferem dos demais grupos. Além disso, há evidência empírica de que nos países em desenvolvimento existem profundas diferencas culturais entre os diversos grupos sociais que os compõem. É possível ainda, com base nos trabalhos sobre a América Latina de Lipset (1968) e Wagley (1968), afirmar-se que essas sociedades, ao nível do urbano, possuem dois grupos sociais básicos que compõem duas subculturas profundamente diferenciadas. O primeiro grupo forma uma subcultura de elite em que se compartilham valores comuns da classe média ou das classes mais altas dos países ricos e industrializados; o segundo grupo, possue uma subcultura popular que se caracteriza, em termos antropológicos, por compartilhar os valores do proletariano urbano da América Latina (grandemente influenciado, ainda, por valores rurais - conforme Wagley, 1968:105).

Como nosso objetivo é pôr em discussão as causas que levaram o problema do habitat urbano brasileiro a uma situação próxima ao impasse diante da atual conjuntura, é necessário que se busque entender os mecanismos que conduziram nossa sociedade a tal situação. Em primeiro lugar, devemos ter a honestidade de reconhecer que a condução da gerência dos problemas urbanos brasileiros tem estado nas mãos de uma elite (intelectual, governamental e empresarial) que é predominantemente oriunda da classe média ou alta e que, portanto, possui valores bastante diversos daqueles que constituem a maioria da população nacional. Essa elite, antes de mais nada, possui características básicas e co- 
-muns aos países do Terceiro Mundo. Conforme Keyfits (1982:651) "o estilo da classe média tem sido ensinado ao Terceiro Mundo pelos Estados Unidos e, também, de certa forma pela Europa. Consiste na posse de residências com sistemas centrais de aquecimento e/ou refrigeração, equipadas com televisões e geladeiras, automóveis, e a aquisição de alimentos e outros produtos básicos no auto-serviço dos supermercados. Tal estilo de vida é encontrado tipicamente em cidades, com ruas pavimentadas, que possuem entre si uma rede de estradas pavimentadas e serviços de transportes aéreos... Pode-se duvidar da existência de uma cultura da pobreza universal - os pobres parecem reter melhor sua maneira nativa e diferenciada - porém certamente existe uma cultura universal de classe média..."

Essa cultura de classe média, flagrante no Brasil, também não foge à regra geral do relativismo cultural, assim sintetizada por Herskovits (1960:351): "Julgamentos são baseados em experiências e a experiência é interpretada por cada indivíduo em termos da sua própria 'enculturação' ".

Isto significa, portanto, que os julgamentos (ou avaliações) de situações econômicas, sociais, tecnológicas, ou quaisquer outras, emitidos por um grupo social, se baseiam em sua própria experiência de vida (e 'enculturação'), o que o leva, em uma situação transcultural, a idealizar paradigmas dos outros grupos de forma muito semelhante a seu próprio paradigma. Como este, ao nível do cotidiano da classe média, se funda em padrões alienígenas em virtude do seu processo de 'enculturação'7, é perfeitamente possível entender a causa das divergências entre, por exemplo, conceitos de qualidade de vida para o país definidos pela classe média e as aspirações da população em geral.8

Essas considerações, obviamente, colocam em xeque a autovisão idealizada da elite no que se refere a um projeto de nação. Se por um lado ela ritualiza, sempre que pode, esse projeto como "uma grande communitas onde raças, credos, classes e ideologias comungam pacificamente ao som do samba e da miscigenação racial(...)" (Matta; 1973:123), pelo outro ela continua projetando sobre a sociedade nacional seu pradigma de classe média internacionalizada. Assim, é comum notar-se uma profunda dicotomia entre a ação e a ideologia do discurso profissional ou acadêmico dos vários grupos envolvidos com o problema do habitat urbano no Brasil. Estes, como observa Matta (ib.: 122), "quando se trata de buscar uma imagem totalizadora de sua realidade social (...) parecem preferir assumir os aspectos conservativos de sua sociedade, deixando de lado as estruturas inerentes às rotinas do mundo cotidiano (conforme Weber, 1943:388 ss.)."

\section{Um paradigma alternativo para o habitat urbano brasileiro}

Ora, se se admite que os paradigmas da elite e do povo são diferentes, é possível também admitirse que tais diferenças se reflitam nos comportamentos de ambos os grupos com relação ao entendimento do espaço que os cerca. ${ }^{9} \mathrm{~A}$ elite, em conseqüência de sua 'enculturação', baseada em padrões forâneos tende a analisar o habitat urbano desde uma concepção paramétrica, importando acriticamente métodos e técnicas (sofisticados) dos países considerados desenvolvidos. Além disso, dentre as ciências que são mais freqüentemente utilizadas para a análise e a manipulação do problema urbano, estão a economia e a sociologia, as quais, com o desenvolvimento do ferramental teórico-matemático das últimas décadas, foram levadas àquilo que Belshaw (1976:11) classifica como uma "ênfase restritiva e mecânica na interpretação do conceito de bem-estar social".

No que diz respeito aos problemas do habitat urbano brasileiro, tal tendência tem levado a atitudes ambíguas no tratamento da realidade urbana brasileira. Assim, são freqüentes os casos em que é enorme o hiato entre o discurso político ou técnico e a proposição de ações concretas. Se, de um lado, se fala de reformas da realidade social, de outro, propõem-se investimentos urbanos que tendem não só a concentrar renda mas que, também, são tecnológica e culturalmente inadequados para a maioria da população. Essa situação, encontradiça em todos os níveis da sociedade - com óbvios reflexos sobre o espaço urbano - é descrita da seguinte forma pelo ministro Hélio Beltrão em recente entrevista: "Evidentemente isso la crise econômica internacional) vai implicar em ajustar o perfil da nossa indústria gradualmente no perfil real de renda, 'porque a nossa indústria' se criou por meio de um processo de substituição de importações e em muitos casos 'importou modelos com um perfil de renda muito superior ao nosso'.

Nada impede que fabriquem produtos sofisticados, mas, na realidade, o nosso perfil de renda não se ajusta a eles. Acabamos nos defrontando com o problema da escassez de mercado... 'O Brasil é seduzido' (por um problema cultural) 'pelo suntuário, pelo aparatoso, pelo sofisticado' " (Beltrão, 1982).

Dentro dessa linha de raciocínio, pode-se defrontar com o problema do desenvolvimento urbano e aí detectar a importação acrítica de modelos de desenvolvimento ou processos tecnológicos de alta sofisticação, incapazes de atender às necessidades globais de desenvolvimento da sociedade brasileira. Nesse campo, encontraremos, com razoável 
facilidade, modelos de densidade e de uso do solo que induzem ao espraiamento das cidades em flagrante oposição à política de transportes que teoricamente pretenderia buscar a redução do consumo de energia. Tais modelos, paralelamente, incentivam também a concentração de densidades de tráfego na parte central das cidades, gerando sérios problemas de congestionamento de trânsito. Para solucioná-los, então, são exigidos, freqüentemente, pesados investimentos em desapropriações, expansão do sistema de controle de tráfego, introdução de novos e sofisticados modos de transporte etc., os quais, em última instância, beneficiam apenas uma limitada parcela da população urbana, em detrimento, por exemplo, das populações periféricas carentes.

Ainda nessa perspectiva, deve-se mencionar que os altos custos da urbanização nos países em desenvolvimento se dão também por conta de privilegiar opcões por tecnologias sofisticadas, principalmente nos campos do saneamento básico e dos transportes. Por exemplo, Linn (1982:636) menciona que "tecnologias de baixo custo em saneamento, tais como fossas negras ou tanques sépticos, não têm sido consideradas por engentieiros sanitários, os quais têm preferido os sistemas muito mais dispendiosos de redes de esgoto". Tais sistemas, baseados em padrões desenvolvidos nos países altamente industrializados, estão freqüentemente acima da capacidade de pagamento da expressiva maioria das populações urbanas dos países pobres. (Conforme ib.: 634). Esse mesmo fato ocorre em outros setores, como os de comunicação e abastecimento, onde também a disparidade no nivel de atendimento aos diversos grupos sociais pode ser atribuída a excessos de sofisticação tecnológicas.

Feita essa rápida análise do problema, é possível, então, empiricamente, considerar que o trato dos problemas urbanos em um país como o Brasil deveria atentar para três pontos básicos:

a) disciplina na observação do fenômeno urbano brasileiro em todos os seus aspectos, principalmente no que diz respeito às inter-relações entre o aspecto cultural e a economia e a tecnologia dos diversos grupos sociais envolvidos no processo de desenvolvimento urbano;

b) enfoque interdisciplinar e multissetorial na condução de uma política urbana nacional que estimule o desenvolvimento de modelos, padrões, e tecnologias autóctones capazes de atender às necessidades do crescimento urbano, considerando que é imperativo manter-se altas taxas de geração de empregos, baixo custo financeiro de investimentos e eqüidade na distribuição dos benefícios;

c) estímulo a um processo gradual de descen- tralização político-administrativo que confira, a médio prazo, maior autonomia aos estados e municípios, para que estes - que são o espelho da diversidade urbana que configura o país - sejam capazes também de colaborar no desenvolvimento de um novo paradigma de um Brasil urbano, mais brasileiro, mais regionalizado e mais eqüânime com a totalidade de seus cidadãos.

Estes três pontos básicos devem ser considerados sob um prisma de médio e longo prazo, posto que preconizam a emergência de um novo paradigma para o conceito de desenvolvimento urbano. $\mathrm{O}$ que se deveria buscar a partir dessa postura seria o desencadeamento de um processo de inovação radical, tanto no campo teórico-científico como no campo tecnológico - em oposição ao processo 'normal' de inovação incremental que tende a reforçar o paradigma vigente (conforme Kuhn, 1962). Em suma, o que se propõe é a busca de uma oportunidade para "se construir uma sociedade compativel com seu meio ambiente físico (e cultural), condição necessária para a sobrevivência a longo prazo...' (Herrera, 1983) de qualquer sociedade que pretenda ser independente e soberana.

A luz dessa perspectiva de inovação radical tentaremos, então, interpretar os três pontos descritos anteriormente. O primeiro deles aponta para a necessidade de organizar - disciplinar - a observação do fenômeno urbano brasileiro. Isso significa que o início desse processo inovador se daria a partir de uma revisão teórica dos conceitos básicos de desenvolvimento urbano e de qualidade de vida urbana. A reavaliação de tais conceitos, desde um ponto de vista não-etnocêntrico, permitiria desencadear um processo de retomada de consciência da realidade nacional, tal como de fato ela é (isto é, diversificada econômica, tecnológica, social e culturalmente), e que, enquadraria, então, pelo menos culturalmente, como a realidade de um país apenas parcialmente 'assimilado' (conforme David, 1982) ao Mundo Ocidental. Embora essa revisão devesse ser iniciada no âmbito acadêmico, não deveria circunscrever-se a esse. Caberia também à classe política, mediante respectivos mecanismos de expressão, disseminá-la entre a sociedade, exibindo a proposta do novo paradigma com a determinação de um porta-bandeira. De nada valerá esse esforço se não forem a ele engajados todos os estratos sociais ${ }^{10}$, de maneira participativa - não à la mode dos public hearings anglo-saxônicos - mas à la mode que o próprio país ${ }^{11}$ deve inventar dentro do seu contexto cultural e político. Essa postura exigirá, por vezes, que se ouse assumir que o desenvolvimento urbano nacional deve testar modelos autóctones, ainda que por métodos de ensaio e erro. Estes, então, ao invés de se legitimarem 'internacionalmente', necessitarão de legitimação nacional por intermédio da li- 
- vre expressão dos seus cidadãos.

O segundo ponto, que aborda os problemas da interdisciplinaridade e da multissetorialidade, toma como base o pressuposto de que se constitui erro científico e metodológico a abordagem do problema urbano a partir de um enfoque setorial. Também enfatiza o estímulo ao desenvolvimento de modelos, padrões e tecnologias autóctones.

Essa posição, longe de xenofobia, intenta marcar um propósito que reconheça que a realidade do país não the permitirá prosseguir na busca do paradigma de desenvolvimento hoje exibido pelas sociedades americara e européia. Aqui também se pressupõe que o espaço urbano, desde uma perspectiva integral, é produto e reflexo de uma sociedade e que, portanto, se caracteriza como um artefato cultural. Por isso mesmo, os condutores de uma política urbana inovadora e a Intellingentzia que os apoiasse ou criticasse teriam que assumir novos padrões 12 para a avaliação do desempenho dessa política que, antes de mais nada, deveria ser singular como o é o próprio país. Isso significa que os padrões atualmente utilizados para todos os níveis de serviços urbanos deveriam sofrer uma reformulacão radical, que permitisse que o Brasil, como um todo (e democraticamente), se readaptasse a esse novo paradigma de desenvolvimento, mais compativel com o seu potencial econômico, tecnológico, industrial, social e cultural.

Finalmente, quanto ao terceiro ponto, que propõe o estímulo gradual à descentralização político-administrativa, é necessário que se diga que ele decorre do fato de se reconhecer a existência de um sem-número de 'Brasis urbanos' que necessitam de um tratamento diferenciado, para a efetivação realística de uma política nacional de desenvolvimento urbano. Tal diferenciação, porém, não deveria implicar o desconhecimento das inter-relações de causa e efeito que se estabelecem entre os diversos pontos da malha urbana nacional e que se refletem na configuração urbana do país como um todo. Assim, por exemplo, o fracasso de uma política agrária no Nordeste, associado à incapacidade da rede urbana regional de prover empregos e servicos capazes de reter o fluxo emigratório, certamente afeta em algum momento a rede urbana das outras regiões. Estas, envolvidas numa cadeia de eventos não controlados, poderiam em curto prazo deparar com sua capacidade de absorcão saturada e, conseqüentemente, sofrer um processo de desagregação econômica e social que viria, certamente, onerar em primeiro lugar aquelas populações que já estão no limiar da pobreza.

A autonomia municipal, mediante essa descentralização político-administrativa, desempenha papel relevante nessa busca de um espírito federa- tivo, porque é somente por seu intermédio que se conseguirá levar para mais próximo dos cidadãos o debate das soluções dos problemas que os afligem. É ali, no seu cotidiano, no espaço imediato que os cerca, que o habitat urbano assume a sua mais complexa e definitiva expressão. É ali, na escala do bairro e do município, onde a casa representa simbolicamente o cosmos de um - o eu - que se inicia o processo de identificação do homem com sua sociedade e com sua cultura (conforme Cooper: 1974). É ainda, no espaço citadino subjacente à casa, que o urbano se configura por intermédio da rua. Da rua que "como methodos, é o meio fundamental de elaboração da cidadania e da civilidade. [onde] A cidadania é a convicção da autopertinência a um universo social que compartilha um conjunto de representações e relações sociais. A cidadania, mais do que um exercício formal, é o exercício da responsabilidade com relação ao que é comum" (Santos e Vogel; 1981:130).

\section{Diretrizes e soluções possíveis}

As seç̃es anteriores deste artigo procuraram enfatizar que, em uma sociedade heterogênea econômica, social e culturalmente, como a brasileira, interagem e coexistem vários grupos sociais que exigem tratamentos diferenciados para a promoção do seu desenvolvimento.

A aceitação desse fato implica que o paradig ma do desenvolvimento nacional não mais seja moldado apenas partindo-se dos objetivos de um único grupo de elite que, como apontado anteriormente, busca mimetizar padrões de qualidade de vida modelados na classe média dos países ricos. Portanto, para que a sociedade brasileira como um todo venha, paulatinamente a beneficiar-se dos frutos de um processo de desenvolvimento, será necessário que, a curto prazo, se redesenhe um novo paradigma de sociedade que inclua, em seu formato, outros padrões de qualidade de vida mais adequados à nossa realidade. Em virtude da existência, ainda, de expressivas desigualdades regionais associadas a um processo concentrador das atividades produtivas em um relativamente pequeno número de centros urbanos (et pour cause) densamente populosos, é necessário que se enfatize aqui que a busca desse novo paradigma para o habitat urbano nacional deverá implicar também uma política de redistribuição espacial das atividades produtivas.

A seleção do que se fazer deveria ser orientada mediante critérios que assegurassem a criação, manutenção e expansão de ambientes favoráveis ao desenvolvimento de atividades produtivas, à diminuição das condições de pobreza e miséria e à limitação e redução de desigualdade de renda, riqueza e oportunidades. Mais especificamente, a escolha de 
projetos e ações urbanas por parte do setor público deveria, necessariamente, perseguir: a) a eliminação das desigualdades na incidência de custos e benefícios oriundos da provisão de serviços de infra-estruturas públicas; b) maior acessibilidade a serviços e equipamentos a todas as camadas da população urbana; c) uma baixa utilização de recursos de capital e de tecnologias complexas; d) maior utilização possível de recursos de mão-de-obra, empreendimentos e materiais locais; e) maior participação da comunidade quanto à manutenção e controle do seu habitat e também na seleção de ações, atividades e projetos que 0 afetem.

Estabelecidos esses critérios que devem pautar as políticas, planos, programas e ações no campo do desenvolvimento urbano, devemos discorrer brevemente sobre algumas das principais diretrizes para uma estratégia que objetivaria moldar novo paradigma do habitat urbano brasileiro.

A primeira dessas diretrizes, realtiva à institucionalização realista de uma formulação autóctone de planejamento urbano, refere-se à necessidade de se reservar um papel estratégico e privilegiado aos estados na formulação e implantação da política urbana. Isso se justifica principalmente em função da carência de recursos humanos especializados ao nível dos municípios que impossibilita a montagem de equipes profissionais de planejadores na maior parte deles. Privilegiando-se a ação do nível estadual não há que se temer a perda da autonomia municipal, pois, como bem diz Rômulo de Almeida, planejamento e centralização de certas decisões não são necessariamente incompatíveis com autonomia municipal e autogoverno. ${ }^{11}$

Uma segunda diretriz diz respeito ao estabelecimento - efetivo e não meramente retórico nas organizações estaduais ou municipais de planejamento, de mecanismos capazes de articular, coordenar e integrar as ações setoriais da babel de entidades federais, regionais e metropolitanas etc., que têm repercussões diretas e indiretas sobre o habitat urbano. Conseqüentemente, haveria necessidade de se instituir programas que visassem dotar essas agências estaduais ou municipais de planejamento com mecanismos mais simples e mais eficientes tanto de coleta e recuperação de informações como de programação, monitoramento e avaliação do processo de implementação de suas políticas de intervenção no espaço urbano.

Uma terceira diretriz é relativa à adoção de instrumentais jurídico e tributário que viabilizem os objetivos da política urbana, fortalecendo o poder de intervenção dos governos municipais quanto ao uso e destino do solo urbano. Dentre as medias que urgiriam ser adotadas, devem ser consideradas: a) instituição do direito de superfície; b) o parcelamento e urbanização compulsória de áreas ociosas, além do estabelecimento do direito de preferência para o município na compra de imóveis; c) simplificação dos procedimentos administrativos e cartoriais de regularização de posse e construção em programas habitacionais de interesse social; d) efetiva utilização da contribuição de melhoria e da taxação progressiva, mediante imposto predial e territorial, de áreas ociosas e já dotadas de infra-estrutura; e) desburocratização dos procedimentos de aprovação de projetos habitacionais individuais ou coletivos etc.

Finalmente, a quarta diretriz propugna por uma maior participação da população no processo de tomada de decisões relativas ao desenvolvimento urbano, que se justifica na medida em que nos conscientizamos de que não basta quantificar e qualificar tecnicamente problemas e carências para que possam ser resolvidos. Embora reconheçamos que ainda não se acham esgotados os mecanismos tradicionais de representacão política, como as câmaras municipais e assembléias legislativas estaduais, há mister também de reservar um maior espaço e importância para formas populares de organização e intervenção da comunidade em assuntos e matérias de interesse direto. Trata-se aqui tanto de assegurar uma maior amplitude de ação aos mecanismos políticos tradicionais, como também de torná-los mais flexiveis para que possam acomodar iniciativas oriundas da própria comunidade.

As diretrizes e os critérios anteriormente apontados indicam a orientação a ser adotada quanto à organização espacial, seja em nível nacional, regional ou local. ${ }^{14}$ Para cada uma dessas escalas ou niveis deveriam ser explicitadas políticas e programas que favoreçam o desenvolvimento das capacidades produtivas, atenuando as condições de pobreza e minorando as desigualdades sociais. Dadas as limitações e âmbito do presente artigo, restingimos aqui a indicações gerais que apontam para o favorecimento de tecnologias 'adequadas' que se caracterizariam pela pequena escala e pela promoção de empreendimentos manufatureiros e comerciais locais. Numa escala nacional e regional, essa orientação implicaria, necessariamente, em uma mudança de ênfase das grandes obras para projetos de menor porte que, descentralizando os investimentos públicos, ampliassem o leque de oportunidades para as pequenas e médias empresas. São exemplos desses projetos as micro e mini-usinas hidrelétricas, as minidestilarias de álcool, as estradas vicinais, os postos de saúde e clínicas comunitárias e as escolas técnicas secundárias que se contraporiam às grandes barragens, auto-estradas, grandes hospitais-escola, campi universitários etc.

No nivel urbano e local, dada a premente necessidade de otimizar a utilização de capital e de re- 
cursos - humanos, naturais e industriais - , deveriam ser evitadas, nos programas e projetos de expansão urbana, tanto as soluções em altura, excessivamente verticalizadas, como as de baixa densidade e ocupação rarefeita. De modo geral ambas implicam em maiores custos de urbanização. ${ }^{15} \mathrm{~A}$ adoção generalizada das primeiras em geral tende a acentuar a dependência do país quanto a tecnologia importadas de capital intensivo e alto consumo de energia, tais como os sistemas modernos e sofisticados de iluminação pública, coleta e tratamento de resíduos sólidos e líquidos, transporte de massa etc. A utilização das segundas tende a agravar as desigualdades sociais, diminuindo a produtividade dos investimentos públicos ou mesmo tornando-os praticamente inviáveis. O padrão ótimo estaria, provavelmente, em um ponto intermediário relativo a formulação de soluções de pequena altura e alta densidade.

Quanto à estruturação e organização do espaço urbano propriamente dito, os planos, programas e projetos urbanos (integrados aí os setores habitacionais, de transportes, saneamento etc.) deveriam visar, em uma macroperspectiva - isto é, na escala do conjunto da cidade ou de zonas e bairros - à constituição de morfologias lineares polinucleadas que se desenvolvessem ao longo de corredores de transportes. ${ }^{16}$ Essas deveriam basear-se em tecnologias como a dos ônibus, trolebus ou outras que não acentuassem a dependência do país quanto a combustiveis fósseis ou que não implicassem o pagamento de royalties. Novas normas e padrões de desenho viário deveriam também ser adotadas com vistas tanto a menor impacto ambiental como a maior segurança e economia de gastos com pavimentação. A comparação, por exemplo, das normas viárias urbanas britânicas e americanas, respectivamente formuladas para contextos diversos - o primeiro, de recursos moderados e limitações de espaço, e o segundo, para espaços e recursos abundantes - pode nos dar uma orientação do que se fazer. Para o caso brasileiro, o bom senso sugere a adoção de uma solução intermediária, adaptando elementos de ambos, pois, no Brasil, se os recursos são escassos, inexistem as limitaç̃es de espaço, pelo menos teoricamente. Daí ser razoável imaginarse a adoção de faixas de domínio público realtivamente generosas associadas a pistas de rolamento de largura reduzida. ${ }^{17}$

O estabelecimento de diretrizes para uma política habitacional, conseqüentes com o novo paradigma, deveria partir da constatação da importância, e significativo volume, que as áreas ditas degradadas ou subnormais têm no estoque total de habitações. Especialmente nas grandes cidades e metrópoles, os programas e projetos habitacionais deveriam evitar que os preconceitos culturais ou estéti- cos levassem a soluções cosméticas do problema, tais como remoções ou reurbanizações radicais cujos benefícios econômicos e sociais gerados são de caráter duvidoso quanto à sua distribuição. Por isso nesses programas dever-se-ia, necessariamente, levar em conta que, apesar do aspecto precário face aos parâmetros de avaliação de uma cultura de elite, as favelas, alagados ou residências localizadas em loteamentos clandestinos representam uma parcela expressiva do capital habitacional fixo da nação ${ }^{18}$.

A visão tradicional que tendia a percebê-las como estruturas desvalorizadas de caráter essencialmente temporário está sendo finalmente abandonada pelos cientistas sociais e métodos de avaliação do seu valor econômico já têm sido desenvolvidos. ${ }^{19}$ Além do econômico, outros argumentos de ordem social e cultural poderiam ser apresentâdos, para justificar essa orientação em função do grande impacto negativo que os projetos de realocação habitacional produzem sobre o sistema de relações sociais e inter-relações pessoais de uma comunidade; para assegurar sua permanência e direito de moradia as comunidades têm desenvolvido várias estratégias de construção, apropriação e defesa do espaço em que vivem (conforme Santos, 1981 e Santos \& Vogel; 1981). Embora não inserido nos fluxos de comercialização formais, esse estoque habitacional possui um valor de mercado não desprezível para o grupo social que o produz e o utiliza. Em face dessa observação e devido ao fato de que os seus moradores carecem de renda suficiente que os habilite a ingressar no mercado formal, ou mesmo em programas subsidiados pelo Sistema Financeiro de Habitação (SFH), o caminho a seguir deverá freqüentemente pender mais para projetos de urbanização e melhoria progressiva do que para a construção de edificações.

Tendo em vista implantar programas de urbanização dessas áreas ou de novas áreas de expansão das cidades, seria também necessário formular políticas financeiras que possibilitassem uma melhor adequação das necessidades básicas com as possibilidades de pagamento da população. Também seria necessário revisar radicalmente os padrões de provisão de serviços e de infra-estrutura público. ${ }^{20}$ Estes, nas áreas de telefonia, abastecimento de água, coleta e disposição de resíduos sólidos e líquidos, energia (gás e eletricidade etc.) e iluminação pública, deveriam, tanto quanto possivel, ser deselitizados e organizados de uma forma mais comunitá. ria do que individualizada. Outra condição a ser perseguida seria a pesquisa de tecnologias e métodos simplificados - e de baixo custo - de construção, manutenção, ampliação e melhoria progressiva das redes, de forma a possibilitar a extensão dos servicos e infra-estruturas a todos os estratos da população. 
Finalmente, para que se obtenha um razoável perfil desse conceito de tratamento integrado dos diversos setores que afetam o habitat urbano, convém fazer algumas considerações sobre o problema dos transportes urbanos. Sob uma ótica social, o transporte afeta fundamentalmente o cotidiano de milhares de pessoas. A capacidade de mobilidade das populações é uma condição imprescindivel, embora não suficiente, à sua participação nas vantagens do sistema urbano.

Dentro da perspectiva econômica, no que diz respeito às relações sociais, o transporte mantém muitas vezes com a sociedade uma relação dialética, principalmente no que tange a valores imobiliários e uso do solo urbano. Isso se verifica na própria experiência brasileira, onde avaliações dessa experiência tem demonstrado que o benefício aparente de alguns projetos não concretiza na realidade as previsões dos planejadores.

Os impactos de modificação no sistema viário sobre o uso do solo e o custo da terra provocam freqüentemente reajustes na estrutura econômica e social que fazem com que o benefício gerado, originalmente destinado a uma parcela específica da população, tenda a ser absorvido por outros grupos sociais em detrimento do beneficiário em vista. Esse tipo de resultado é conseqüência das limitacões do ferramental analítico usado tradicionalmente para o planejamento de projetos de transportes. Em primeiro lugar, porque a tecnologia de transportes, oriunda de países desenvolvidos, acarreta um alto grau de sofisticação que se reflete nos padrões de uso corrente. Em segundo, proque seu uso e aplicação iniciais se deram em sociedades econômica e culturalmente mais homogêneas, o que permitiu que sua absorção pela sociedade se realizasse de forma menos traumática. (Esta afirmativa deve ser considerada apenas em termos quantitativos de população atingida, e beneficiada. Veja-se Schermer, 1975.)

Portanto, a formulação de políticas de transporte adequadas a um novo paradigma da sociedade deveria induzir à utilização de tecnologias modais já de domínio nacional e de custo relativo baixo ou intermediário (trens suburbanos, ônibus, etc.), cujo consumo de energia não viesse a onerar a balança de pagamentos. Sua adoção combinada com uma mais efetiva e rigorosa administração de operação dos sistemas de tráfego viário urbano implicaria o abandono dos privilégios (diretos ou indiretos) até o presente momento conferidos à circulação do automóvel privado ou a sistemas de transporte de massa onerosos e sofisticados, como os metrôs.

Sugere-se ainda o reconhecimento de modos informais ou 'piratas' de transportes urbanos (Kom- bis, táxis-lotações, compartilhamento remunerado do automóvel privado, etc.), através de sistemas de organização e controle simplificados que permitam a sua legalização e desenvolvimento como modos complementares ao sistema formal. Essa alternativa, pelo volume de usuários de baixa renda existente, apresenta um potencial econômico e social que pode contribuir expressivamente na geração e distribuição de renda a partir de iniciativas individuais ou microempresariais. A formulação de tais políticas, dentro de um contexto integrado de habitat urbano, permitiria a indução de melhor ocupação e utilização racional do solo urbano e contribuiria significativamente para a consecução dos objetivos de eqüidade de um novo modelo de desenvolvimento urbano.

\section{Conclusão}

Dentro das limitações de profundidade e espaço inerentes a um artigo, procurou-se expor nesse texto os seguintes pontos básicos: a) o desenvolvimento do habitat urbano brasileiro historicamente, como preocupação governamental, não tem merecido a atenção que lhe é devida, sendo ordinariamente considerado como um mero somatório de intervenções setoriais no âmbito das cidades; b) nas áreas urbanas, o país apresenta grandes desigualdades, não só econômicas e sociais, mas também culturais, entre a elite de classe média - intelectual, governamental e empresarial - e os grupos de baixa renda; como conseqüência, ambos possuem paradigmas diferenciados de bem-estar e qualidade de vida; c) o paradigma da classe média aproxima-se de padrões de qualidade de vida exibido pelas classes médias dos países altamente industrializados e, portanto, preconiza padrões de consumo le de desperdício) incompatível com as condicões econômicas, tecnológicas e culturais do Brasil; d) como conseqüência dessa discrepância de paradigmas, os padrões utilizados para implementar o desenvolvimento das cidades brasileiras são elitizados e etnocêntricos e discrepantes com a capacidade de pagamento da maioria das populações urbanas. Em decorrência disso, nossas cidades exibem sofisticadas ilhas de modernismo que se contrapõem a enormes áreas de periferia carentes de serviços públicos básicos; el para que se modifique tal situação, é necessário um esforço de toda a sociedade no sentido de substituirse $\mathrm{o}$ atual paradigma de desenvolvimento urbano que apenas reflete mimeticamente uma realidade importada dos países desenvolvidos - por outro paradigma que venha a refletir a realidade econômica, tecnológica, social e cultural do Brasil. Para tanto, será necessária a modificação dos conceitos básicos padrões de atendimento de serviços públicos; a modificação radical de metodologias de projeto e de planejamento de serviços urbanos; e uma reflexão pro- 
funda - ao nível teórico - sobre os caminhos que se deverá tomar para alcançar um desenvolvimento mais justo socialmente, mais adequado culturalmente e mais viável economicamente.

De tudo o que se disse anteriormente, realçase a magnitude do problema que a sociedade brasileira como um todo - e as elites em particular deverá enfrentar ao encarar com realismo a necessidade de vir a adotar-se, num futuro muito próximo, um novo modelo para o desenvolvimento do habitat urbano nacional. A implantação de tal modelo exigirá, sobretudo, esforços de adaptação por parte da elite a novos conceitos de conforto e até mesmo de estética que correspondam às possibilidades que o país atualmente tem para desenvolverse, social e economicamente, reduzindo sua dependência externa. A necessidade de adoção de novos padrões não configura necessariamente um simples rebaixamento de qualidade diante dos ditos standards internacionais. Sua concepção dinâmica implica que, embora partindo de patamares modestos, possam, desprovidos de quaisquer mimetismos culturais, ser progressivamente qualificados, refletindo os anseios da nossa própria sociedade.

Finalmente, pressupõe-se como indispensáveis o maior envolvimento e participação dos plenajadores e administradores urbanos e municipais no processo e nos debates políticos. Nessa perspectiva, planos, projetos e ações para o desenvolvimento urbano deverão ser formulados numa linguagem traduzivel e facilmente compreensível a todos e não apenas a uma pequena elite de especialistas e universitários iniciados no ramo. Abandonando abstrações e jargões acadêmicos e técnico-profissionais, a tarefa é, democraticamente e em conjunto com todos os setores da sociedade afetados, formular respostas e soluções para os problemas, não do país dos sonhos e fantasias imaginado pela elite, mas sim do país concreto, complexo, pobre, singular e real que aí está para ser visto e compreendido.

\section{Notas}

1. Em 1932 foi criada a Comissão de Estudos Financeiros e Econômicos dos Estados e Municípios e, em 1934, o Instituto Brasileiro de Geografia e Estatística e também o Conselho Técnico de Economia e Finanças. Em 1938 fundou-se o Departamento Administrativo do Serviço Público - DASP - que, dentre suas atribuições, tem as de "profissionalizar a administração e promover a modernização permanente dos sistemas, métodos e processos de gerência administrativa" (conforme Oliveira, 1979:45).

2. SAGMACS - Sociedade de Análises Gráficas e Mecanográficas Aplicadas aos Complexos Sociais.

3. Para uma avaliação e discussão do papel desempenhado por essa vertente, ver Sampaio (1982) e Espaço \& Debates (1982; IV:1, 137-172)

4. Os CEMUANs - Cursos de especialização em metodologia e projetos de desenvolvimento municipal, foram realizados pelo
IBAM, em diversos momentos sob a coordenação dos arquitetos Francisco Whitacker, Adina Mera e Marcos M. Rissin.

5. O SERFHAU e o BNH, criados pela lei 438 de 21 de agosto de 1964 , têm sua origem em ações anteriores a 1964, entre as quais vale citado o Seminário de Habitação e Reforma Urbana realizado no hotel Quitandinha, Petrópolis. Sobre o assunto consultar Serran (1976)

6. Diz-şe aqui "desparecimento quase completo da ação municipalista" porque também na SEPLAN criou-se em 1972 a Secretaria de Articulação com os Estados e Municipios (SAREM), que manteria muitas das atribuicōões técnicas dos extintos SENAN e SERFHAU relativos à modernização das administrações municipais.

7. "Quando se considera que certos conceitos intangiveis tais como o certo e o errado, o nomral e o anormal, o belo e o feio são absorvidos enquanto uma pessoa apreende a maneira de viver do grupo em que ela nasceu, nota-se que se está lidando com um processo de primeira importância. Até os fatos do mundo físico são discernidos através do crivo da 'enculturação'; por isso 'a percepção de tempo, distância, peso, tamanho e outras realidades é medida sempre pela convenção de cada grupo'." (Herskovits, 1960:351; ênfase dos autores)

8. Apenas para exemplificar, mencionam-se aqui alguns casos flagrantes e representativos dessa dicotomia cultural: o conjunto habitacional de Pedregulhos, a Cruzada São Sebastião, a Vila Kennedy (todos no Rio de Janeiro), os autódromos construídos na década de 1970 e o parque Rogério Pithon Farias (em Brasilia). Em todos esses exemplos buscou-se atender ao anseio da população, porém, como tiveram sua construção baseada em um paradigma idealizado pela elite, os resultados foram insatisfatórios tanto em relação ao aspecto social como em relação ao aspecto econômico. Muitas dessas obras foram abandonadas à própria sorte a um custo social alto, ou exigiram, fora sua manutenção, altíssimos gastos financeiros. Não houve entre elas e a comunidade a que se destinavam uma relação de escala culturai que permitisse sua apropriação pelo grupo

9. O espaço urbano, ao longo desse artigo, é considerado como um artefato cultural, produto dos grupos sociais que nele habitam e dos fatores econômicos, sociais, políticos e culturais sobre eles atuantes.

10. "No plano político, finalmente, parece pouco provável que as conquistas libertárias sejam compartilhadas igualmente em sociedade que apresenta, no econômico e no social, tão grandes disparidades, o que faz com que elas sejam entendidas, concretamente, mais como 'precondições formais à prática da democracia, necessárias mas insuficientes para engendrar processo de repolitização que se afirme como amplamente participativo'." (Cavalcanti de Albuquerque; 1982)

11. Vide reportagens sobre os municípios de Lages (SC) e Boa Esperança (ES) publicadas, respectivamente, em Isto é de 20 de agosto de 1980 , p. 28-30 e Jornal do Brasil de 26 de julho de 1981 , 1. caderno, p. 26

12. "Muitas pessoas pensam sobre o desenvolvimento tecnolć gico como a evolução natural de melhoramentos incrementais de um elemento sobre outro. Tal atitude encoraja o desenvolvimento sucessivo de sistemas urbanos mais e mais complexos, os quais são cada vez mais afastados do controle dos residentes da cidade. Então, quando os benefícios são ultrapassados pelos custos... é tempo de se buscar uma inovação revolucionária." (Hallet e Hess, 1982)

13. "Os dois caminhos não seguem rumos opostos, desde que a comunidade local e o governo municipal sejam, sempre que possível, os intermediários na aplicação dos recursos devidos no 'alto'... e que haja participação democrática efetiva, participação das bases, nas decisőes centrais, em vez de decisões autocráticas." (Almeida; 1977-38)

14. Muitas das proposições aqui apresentadas podem ser encon- 
tradas em vários autores. Ver entre outros Safier (1974:72-79), Knesi (1982:14-21), Lerner (1982:18-24).

15. Embora a correlação entre densidades urbanas e custos de servicos e infra-estruturas seja assunto controvertido e sujeito a debate, é razoável para efeitos práticos que autoridades urbanísticas procurem determinar pontos 'ótimos' para a mesma. Segundo alguns estudos, os custos variam segundo uma curva em $U$, com o ponto de maior inflexão correspondendo à densidade 'ótima'. Ver Urdaneta (1969:1-42)

16. Conforme Safier; 1974:75. Para recomendações de normas e padrões mais 'adequados' às condições de um país pobre, ver entre outros Caminos e Goethert (1975), Poulton (1982) e Sinduoea (1974)

17. Complementarmente poderiam ser também adotadas, para o projeto de vias e ruas de caráter secundário, versões simplificadas e adaptadas a cada circunstância, do chamado Woonerf concept, que visa assegurar entre outros objetivos uma melhor convivência entre pedestres e veículos sobre uma mesma e única superfície de rolamento. Sistemas vários residenciais projetados de acordo com padrões de dimensionamento mais econômico, além de afetarem menos o meio ambiente - menor impacto sobre o lencol freático, na medida em que estes diminuem a impermeabilização do solo - , aumentam também a segurança para a circulação de pedestres em função da menor velocidade de deslocamento a que seriam obrigados os veículos motorizados (Vejase Royal Dutch Touring Club; 1980).

18. Como suporte às proposicões aqui estabelecidas, podem ser citados artigos mais recentes de Hart-Deneke (1982), Stocker (1982), Jimenez (1982) e Hardoy \& Satterthwaite (1982)

19. Conforme Jimenez, 1982. Ver também matéria publicada na Folha de São Paulo de 30 de janeiro de 1983, p.16: Especulação eleva preços de barracos até $\mathrm{Cr} \$ 1$ milhão.

20. Pesquisas e estudos já foram efetuados nesse sentido. A titulo de exemplo de tecnologias simplificadas, ver as proposições apresentadas por Fernando Tudela, Ducan Mara, Neiva Alva e outros no Seminário de Tecnologias Apropriadas para os Assentamentos Humanos, organizado pela FAU-USP, com apoio da CE PAL, do MINTER/CNDU e CNPq (São Paulo, dezembro, 1982).

\section{Bibliografia}

1. ALMEIDA, Romulo O IBAM e o municipalismo no Brasil. Revista de Administração Municipal, Rio de Janeiro, 24(145): 36, 1977

2. ALVA, Eduardo Neiva. Tecnologias apropriadas para a producão de bens e servicos habitacionais. Seminário Tecnologias Apropriadas para os Assentamentos Humanos, São Paulo, MINTERCNDU/CNPq/ONU-CEPAL/FAU-USP, 1982.

3. BELSHAW, Cyril S. The Sorcerer's apprentice, Pergamon Press Inc., New York, 1976.

4. BELTRÃO, Hélio. Beltrão defende a pacificação nacional, O EStado de São Paulo, 19 de dezembro de 1982, p.5, São Paulo.

5. CAMINOS, Horácio \& GOETHERT, Reinhard. Urbanization primer: for design of site and services projects. World Bank, Urban Projects Department, Washington - EUA, 1976

6. CAVALCANTI de Albuquerque R. Habitação e desenvolvimento urbano do Brasil, Revista do Serviço Público, Brasília, 110(02); abr./jun., 1982.

7. COOPER, Claire. The house as a symbol of the self, in Lang, Jon et alii, Designing for human behavior, Stroudsburg, Hutchinson \& Ross. Inc. s.d

8. DAVID, Jacques E. Culture et développement, le purgatoire des économistes, Futuribles, França (52) fev. 1982.
9. Planejamento urbano do populismo aos dias atuais, Espaço \& Debate, São Paulo, 1(4): 137, dez. 1981

10. HALLET, Stanley J. \& HESS Jr., Alfred G. Human scale technology; a new approach to solving urban problems, The Futurist, EUA, jun. p.30, 1982.

11. HARTH-DENEKE, Alberto. Quasi-legal urban land subdivision in Latin America: a solution or a problem for low-income families? Development: Seeds of Change, EUA, 2:50, 1982.

12. HERRERA, Amilcar. Desenvolvimento e meio ambiente, Folha de São Paulo, 1 de janeiro de 1983, p.10, São Paulo, 1983.

13. HERSKOVITZ, Melville J. Cultural Anthropology, Alfred A. Knopf, New York, 1960.

14. JIMENEZ, Emmanuel. The value of squatter dwellings in developing countries, Economic Development and Cultural Chan ge, Chicago 30(4), jul., 1982.

15. KEYFITZ, Nathan. Development and the elimination of poverty, Economic Development and Cultural Change, 30(3), abr. 1982.

16. KNESI, John. Town and country in development from below: the emerging paradigm for the decade. Ekistics, Grécia, 292: 14, jan./fev., 1982.

17. KUHN, T. The structure of scientific revolutions, Chicago, Chicago University Press, 1962.

18. LENER, Jayme. The city and scale: one turn less of the screw Development: Seeds of Change, (2): 18, 1982

19. LINN, Johannes F. The costs of urbanization in developing countries, Economic Development and Cultural Change, Chicago, 30(3), abr.

20. LIPSET, S. M. \& SOLARI, Aldo. Elites in Latin America, London, Oxford University Press, 1968.

21. MARA, Ducan. Tecnologia apropriada para abastecimento d'água e saneamento. Seminário Tecnologias Apropriadas para os Assentamentos Humanos, São Paulo, MINTER-CNDU/CNPq/ ONU-CEPAL/FAU-USP, 1982.

22. MATTA, Roberto da. Ensaios de antropologia estrutural, Petrópolis, Editora Vozes, 1973.

23. OLIVEIRA, Newton et alii. A experiência brasileira em planejamento urbano: formulação de um modelo histórico-descritivo e indicacão de caminhos alternativos. Brasilia, CNPq, 1979.

24. POULTON, Michael $C$. The best pattern of residential streets, American Planning Association Journal, Autumm, 48(4): 466, 1982.

25. REINA, Benjamin. Paraná, Texas, University of Texas, 1973.

26. ROYAL DUTCH TOURING CLUB ANWB. Woornerf: a new approach to environmental management in residential areas and the related traffic legislation, Road Safety Directorate. Haia, ANWB Traffic Department.

27. SAFIER, Michael. Habitat for development. Royal Town Planning Institute; Overseas Summer School. 1974 - Report of Procedings, Exeter, 1974.

28. SAMPAIO, Plinio de Arruda. O plano de ação do governo Carvalho Pinto: planejamento e política no estado de São Paulo em 1959. Espaço \& Debate, São Paulo, 1(4): 127, jun. 1981.

29. SANTOS, Carlos N. F. \& VOGEL, Arno. Quando a rua vira casa, a apropriação de espacos de uso coletivo em um centro de bairro, 2.ed. rev. e atual. Rio de Janeiro, FINEP/IBAM, 1981.

30. SANTOS, Carlos N. F. Movimentos urbanos no Rio de Janeiro. Rio de Janeiro, Zahar, 1981

31. SCHERMER, Julie $H$. Interest group impact assessment in transportation planning, Traffic Quarterly, New York, 24(1), 1975. 
32. SERRAN, João R. O IAB e a política habitacional. São Paulo, Schema Ed., 1976.

33. SINDU/OEA. Normas mínimas de urbanización y servicios públicos - Bogotá, SINDU, 71 p. (Manuales 2) Bogotá, SINDU, 1974

34. WAGLEY, Charles. The Latin American tradition. New York, Columbia University Press, 1968.
35. URDANETA, Alberto. Costos de urbanización, Cuadernos dt la Sociedad Venezolana de Planificación. Venezuela, (66-67): 1-42, out. 1969.

36. TUDELA, Fernando. Tecnologias apropriadas para saneamento básico. Seminário Tecnologias Apropriadas para os Assentamentos Humanos. São Paulo, MINTER-CNDU/CNPq/ONUCEPAL/FAU-USP, 1982 
- 